\title{
Transcriptome analysis of the mobile genome ICEclc in Pseudomonas knackmussii B13
}

\author{
Muriel Gaillard ${ }^{+1}$, Nicolas Pradervand ${ }^{+1}$, Marco Minoia ${ }^{1}$, Vladimir Sentchilo', David R Johnson ${ }^{1,2}$ and Jan Roelof van \\ der Meer*1
}

\begin{abstract}
Background: Integrative and conjugative elements (ICE) form a diverse group of DNA elements that are integrated in the chromosome of the bacterial host, but can occasionally excise and horizontally transfer to a new host cell. ICE come in different families, typically with a conserved core for functions controlling the element's behavior and a variable region providing auxiliary functions to the host. The ICEclc element of Pseudomonas knackmussii strain B13 is representative for a large family of chromosomal islands detected by genome sequencing approaches. It provides the host with the capacity to degrade chloroaromatics and 2-aminophenol.

Results: Here we study the transcriptional organization of the ICEClc core region. By northern hybridizations, reversetranscriptase polymerase chain reaction (RT-PCR) and Rapid Amplification of CDNA Ends (5'-RACE) fifteen transcripts were mapped in the core region. The occurrence and location of those transcripts were further confirmed by hybridizing labeled cDNA to a semi-tiling micro-array probing both strands of the ICEclc core region. Dot blot and semi-tiling array hybridizations demonstrated most of the core transcripts to be upregulated during stationary phase on 3-chlorobenzoate, but not on succinate or glucose.

Conclusions: The transcription analysis of the ICEC/C core region provides detailed insights in the mode of regulatory organization and will help to further understand the complex mode of behavior of this class of mobile elements. We conclude that ICEClc core transcription is concerted at a global level, more reminiscent of a phage program than of plasmid conjugation.
\end{abstract}

\section{Background}

The acquisition of horizontally transferred genes plays an important role in prokaryotic evolution [1]. The colonization of new ecological niches is often enabled by the acquisition of foreign genes, which can be transmitted by a large variety of mobile genetic elements (MGE) present in individual members of the microbial community. In terms of evolutionary success, it is thus interesting to understand how different mobile DNA elements control their mobility and may adapt to their bacterial host [2].

Various classes of MGE are known, the most well-studied of which are plasmids and bacteriophages [3,4]. Plasmids, apart from certain exceptions such as the Fepisome in Escherichia coli, generally occur as extrachro-

* Correspondence: janroelof.vandermeer@unil.ch

1 Department of Fundamental Microbiology, University of Lausanne, Bâtiment

Biophore, Quartier UNI-Sorge, 1015 Lausanne, Switzerland

+ Contributed equally

Full list of author information is available at the end of the article mosomal DNA in the bacterial cell. An important aspect of their life-style, therefore, is to ensure replication, stability and maintenance in the host cell [5], and a variety of control mechanisms have evolved hereto [6]. Conjugative plasmids encode and orchestrate specific machineries to produce the transfer system dedicated to their own distribution (e.g., type IV secretion system) [7]. By contrast, temperate bacteriophages insert into the host's chromosome, where they can remain silent and are co-replicated with the host's DNA for many generations, or are eventually genetically defunctionalized. Feedback regulatory systems silence phage behaviour in the temperate form, but can very rapidly induce the lytic phase (e.g., upon SOS response), upon which thousands of phage particles are produced to commence a new infection cycle $[8,9]$.

More recently, a large new class of DNA elements has been recognized that contributes importantly to bacterial genome evolution via horizontal gene transfer. Most of these have been detected by comparative genome 
sequencing and have in general been named 'genomic islands' (GEI) to portray their foreign character within the host genome [10]. Often, according to the functions encoded by the GEI, they were classified as pathogenicity, symbiosis, metabolic, secretion or resistance islands $[11,12]$. Recently we and others proposed that GEI should be considered an overarching group of elements comprising both phage-like, Integrative and Conjugative Elements (ICE), as well as conjugative transposons [10]. Although GEI are assumed to have been acquired via horizontal gene transfer, for most of them self-transfer has not been tested under experimental conditions. In some cases only GEI excision from its chromosomal location has been observed, which is presumed to be the first step in horizontal transfer [13]. A self-transferable GEI (e.g., ICE, conjugative transposons and other types) can move its excised DNA to a new host, where it can reintegrate with the help of an integrase enzyme at one or more specific insertion sites. GEI transfer can be mediated by conjugation or transduction, either by the element itself or via mobilization by another MGE. For some GEI the conjugation machinery closely resembles that of known plasmid-types, such as that of the SXT element of Vibrio cholerae [14] or the ICEMlSymR7A element of Mesorhizobium loti [15]. For others it is very distantly related to known plasmid conjugative systems, like for ICEHin1056 of Haemophilus influenzae, suggesting them to be evolutionary ancient elements [16]. The findings that many GEI resemble phages by their integrase, but plasmids by their conjugative system [10], suggests they are evolutionary hybrids, which may have global control mechanisms reminiscent of both phages and plasmids. To better understand the global control of such evolutionary hybrid elements and the consequences of the element's behavior for its bacterial host, it would be helpful to have detailed information on their transcriptional organization and regulation, which is presently still very fragmented. The SXT-element, for example, displays a key regulator (SetR) similar to the phage $\lambda \mathrm{CI}$ repressor that is autocleaved upon SOS response, after which SXT transfer becomes strongly induced $[17,18]$. Preliminary regulation studies were also performed on ICEHin1056 [16] and the Pseudomonas aeruginosa elements pKLC102 and PAGI-2 [19], but without attaining a global level.

Our group has been studying a mobile GEI in Pseudomonas, Ralstonia and Burkholderia, called the clc element or ICEclc [20]. ICEclc has a size of 103 kilobasepairs $(\mathrm{kbp})$ and is integrated into the chromosome at the 3 ' 18 -bp extremity of one or more $t R N A y^{\mathrm{Gly}}$ genes by the help of an unusually long P4-type integrase [21-23]. The first half of ICEclc encodes two catabolic pathways involved in chlorocatechol (clc genes) and 2-aminophenol (amn genes) degradation [20] (Figure 1A). The second half contains a large set of syntenic genes that were defined as life-style 'core' for sixteen GEIs originating from different Beta- and Gammaproteobacteria [24]. Among other things, this core has been proposed to encode a type IV conjugative secretion system distantly related to that of ICEHin1056 [16]. In addition, this part of ICEclc is assumed to encode the relaxosome complex needed for conjugation and was shown to bear a regulatory factor controlling excision and transfer [25,26]. ICEclc is transferred from $P$. knackmussii $\mathrm{B} 13$ as donor to e.g., Pseudomonas putida as recipient almost exclusively in stationary phase cultures with frequencies of self-transfer $\approx 10^{-2}$ per donor. Self-transfer rates are highest in stationary phase cells grown with 3-chlorobenzoate and lower with fructose [27]. In line with this, expression of the promoter for the integrase is highest after growth on 3-chlorobenzoate, lower on fructose and essentially absent on glucose [26]. Because of the conservation of the ICEclc core region among different GEIs we were interested to study its transcriptional organization, as a further step towards the understanding of the life-style program of this class of mobile elements.

In order to resolve the global transcription network of ICEclc in P. knackmussii B13, we carried out a combined approach of Northern hybridizations, reverse-transcriptase polymerase chain reaction (RT-PCR), semi-tiling array hybridization and Rapid Amplification of cDNA Ends (5'-RACE). We detected fifteen transcripts, some of which were expressed to high levels in stationary phase cultures, but -- interestingly, not with all carbon sources.

\section{Results}

Transcriptional organization of the ICEclc core region

In order to analyze the transcriptional organization of the core region of ICEclc, we used a combination of conventional molecular techniques and semi-tiling micro-array analyses. The ICEclc core spans the region between nucleotide 50,000 until the left end of the element (position 102,843; ICEclc numbering, GenBank Accession Number AJ617740), and comprises the most conserved stretch among a number of closely related GEI $[24,26]$. Furthermore, it includes the integrase gene at the other side of ICEclc (Figure 1A).

Figure 1 schematically presents the analysis of intergenic regions in the ICEclc core region, whilst combined RT-PCR results are shown in Figure 2. RT-PCR provided a first view of potentially linked polycistronic mRNAs. In a number of cases the clear absence of RT-PCR amplicons coincided with distinct large intergenic regions predicted from the nucleotide sequence (Figure 1B), whereas in other cases gaps were rather unexpected with respect to the close gene organization and could point to mRNA cleavage sites rather than new transcription start sites. This occurred, for example, in the regions between ORFs 62755-63176 (overlapping ORFs), ORFs 66202-66625 (12 


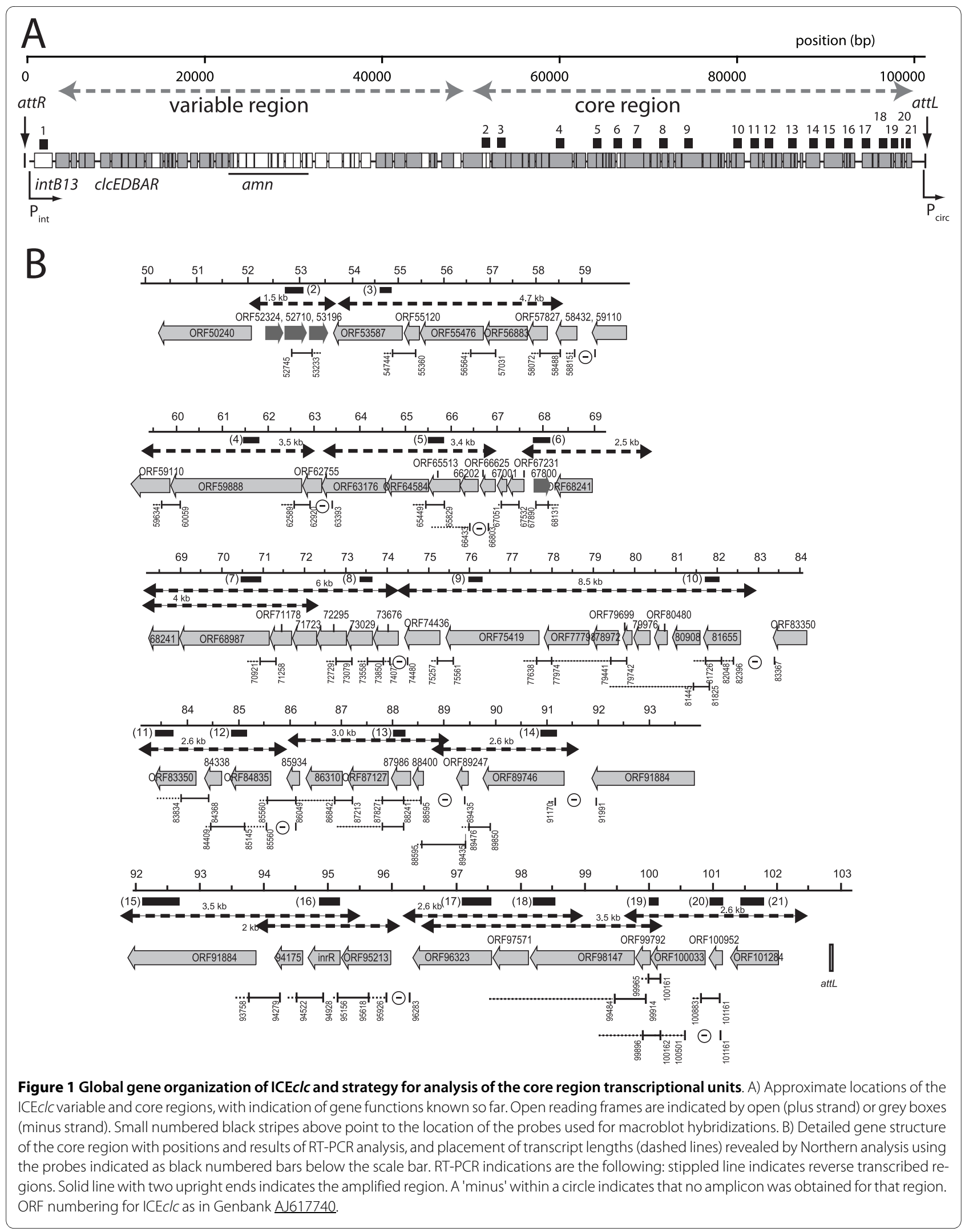




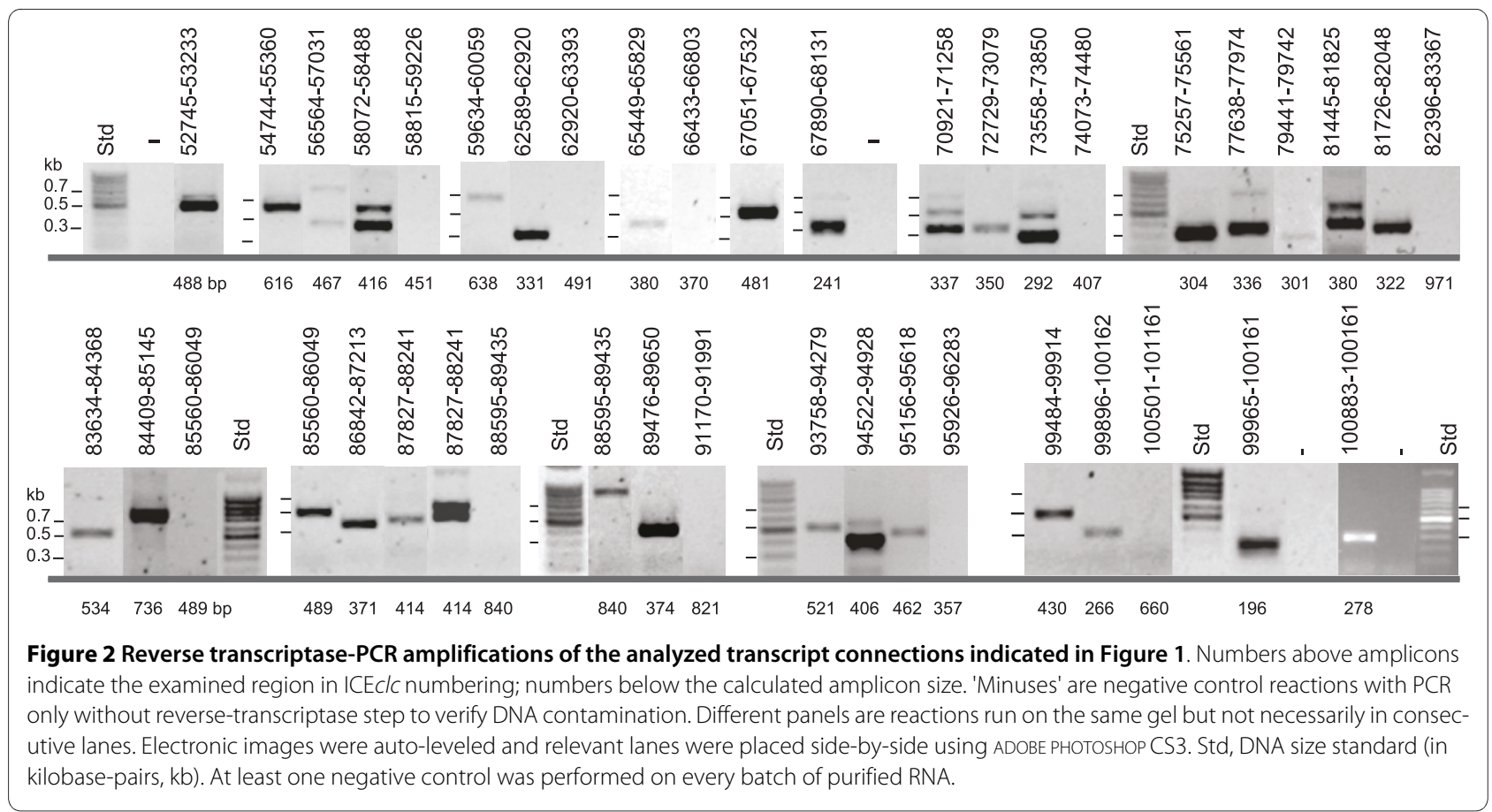

bp intergenic region) and ORFs 73676-74436 (139 bp intergenic region, Figure 1, 2).

On top of the RT-PCR analysis we mapped the length of detectable transcripts by Northern hybridizations of RNA isolated from $P$. knackmussii B13 cultures grown to stationary phase on 3-chlorobenzoate (Figure 3). Arguably, Northern hybridizations do not always produce clear-cut signals and often show multiple bands indicative for mRNA degradation or processing, but for most of the transcript sizes and positions proposed by RT-PCR analysis supporting evidence was provided by Northerns (Figure 1, 3). Even the breakpoints detected between ORFs 62755-63176 coincided with two detectable transcripts of around $3.5 \mathrm{~kb}$ that could be positioned around the gap (Figure 1). The longest detected transcript seems to be formed by an estimated $8.5 \mathrm{~kb}$ polycistronic mRNA that would start upstream of ORF81655 and ending at ORF74436. It is possible, as we will argue below, that this transcript is actually synthesized as a much longer one, but cleaved somewhere in the area of the gap identified by RT-PCR between ORF73676 and 74436. The downstream part would be formed by a $6 \mathrm{~kb}$ mRNA that was detectable by probes for the ORFs 68987 and 73029 (Figure 3). Although a -10 promoter region was predicted upstream of ORF73676 by bioinformatic analysis, several others were predicted in this $8.5 \mathrm{~kb}$ region as well (see below and Table S1). Therefore, promoter prediction was not sufficiently accurate to support or refute the hypothe-

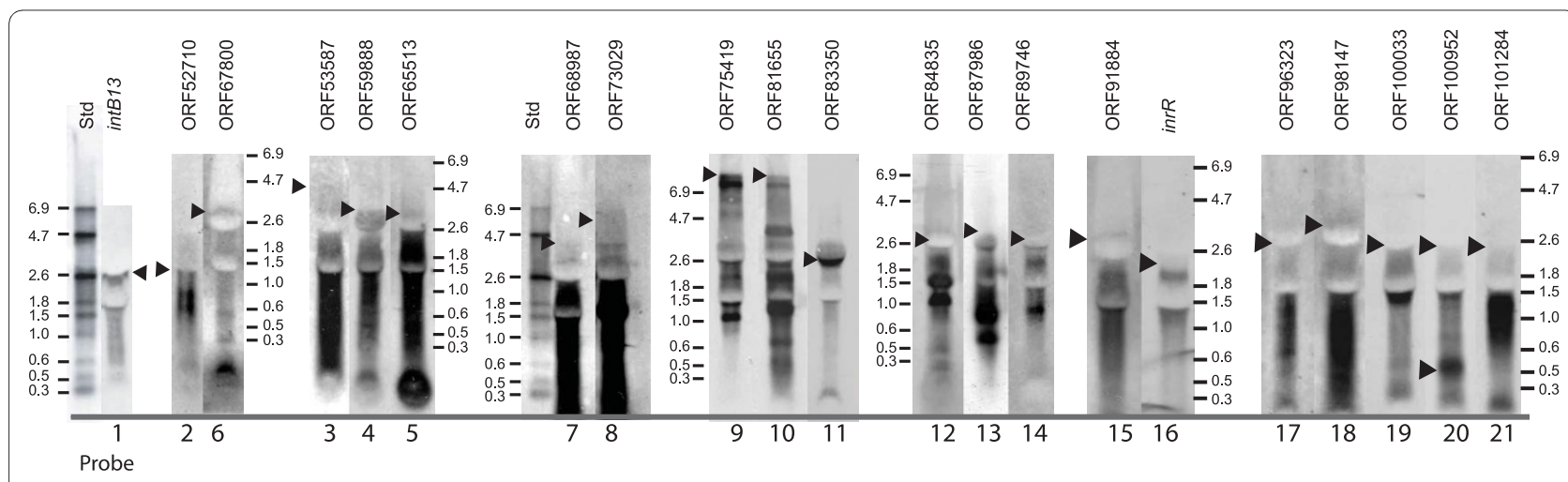

Figure 3 Compiled Northern analysis of transcript sizes in the ICEclc core region on RNA isolated from cells grown to stationary phase on 3-chlorobenzoate. Probe used in hybridization for a respective panel is indicated as the ORF number above and the probe number below, corresponding to the indications in Figure 1. Black triangles point to the largest size determined for the hybridizing transcript. Size indications for each panel in kilobases, based on an RNA size ladder. Electronic images were auto-leveled and relevant lanes were placed side-by-side using ADOBE PHOTOSHOP CS3. 
sis for the 8.5 and $6 \mathrm{~kb}$ regions being transcribed as a single polycistronic mRNA.

\section{Micro-array analysis assisted transcript mapping}

To complement the RT-PCR and Northern analyses, we hybridized Cy3-labeled cDNA synthesized from total RNA isolated from P. knackmussii B13 cultures during exponential growth on 3-chlorobenzoate and during the following stationary phase, to custom-designed semi-tiling microarrays for ICEclc. The semi-tiling array contained a 50-mer probe at approximately every 200 bases over the whole length of ICEclc and for both strands, each in sixfold replicate on the array. We expected that a semitiling array format would permit us to map the position of ICEclc transcripts in a complementary way to the conventional molecular analysis, which would help to reinforce the conclusions drawn on the transcriptional organization of the ICEclc core. Figure 4 shows an overlay of the core gene organization and RT-PCR plus Northern derived transcriptional organization with the average micro-array hybridization signals per probe on the plusand the minus-strand of the ICEclc core region, whilst Table 1 summarizes the transcript details across all three methods. Very strikingly, most of the predicted transcripts follow a clear $5^{\prime}-3^{\prime}$ decrease in signal intensity, the slopes of which were different for each transcript region (see, for example, the region for the long transcript proposed between position 82,000 and 68,000 ). We think the $5^{\prime}-3^{\prime}$ decrease in intensity may partially be caused by the fact that more transcripts are formed near the transcription start, which perhaps are incompletely finished, or by preferential 3'-end degradation. This effect has been noted by others using tiling approaches for transcript determination [28]. Different slopes may be the result of varying $\mathrm{mRNA}$ stability and processing speed.

Semi-tiling array hybridizations confirmed most of the proposed transcripts, including breakpoints, where the slope of the decrease in hybridization intensity as a function of probe position changed abruptly (e.g., regions around position 63,000 and 86,000). An exception here was the RT-PCR detected breakpoint in between ORFs 73676 and 74436, where micro-array hybridizations did not show any aberrant change in slope of signal decrease. From this, therefore, we conclude that the long transcripts of 8.5 and $6 \mathrm{~kb}$ mentioned above actually originate from one $14.5 \mathrm{~kb}$-long polycistronic mRNA starting at ORF81655 and ending downstream of ORF68241. This transcript would then be rapidly processed in the indicated breakpoint area, although this should be confirmed by alternative techniques.

For one other region the pattern of 5'-3' decreasing slope did not match the hypothesis of a single transcript predicted from RT-PCR and Northern. This occurred in the area around 92,000 to 96,000 where RT-PCR had predicted a continuing transcript covering a four-gene cluster including ORF91884 (putatively encoding a DNA topoisomerase) [20], ORF94175 (putative single-strand DNA binding protein), inrR (the proposed IntB13 activa-

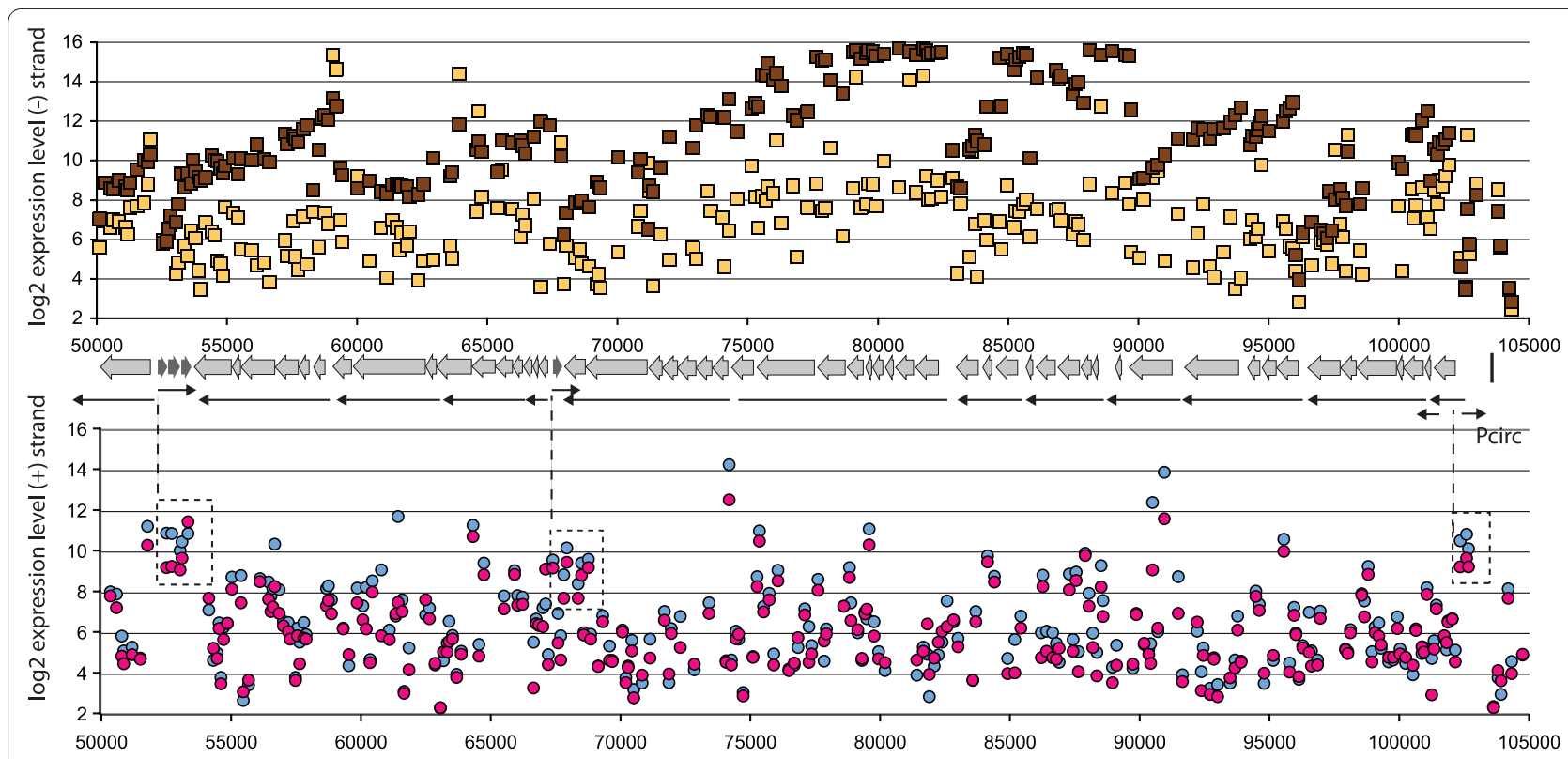

Figure 4 Transcriptome of the ICEclc core region. Shown is a compilation of micro-array hybridizations with minus- (top image) and plus-strand located probes (bottom image), both for exponential (yellow squares and blue circles) and stationary phase cultures (dark squares and pink circles). Data points are mean hybridization signals (on log2-scale) from six replicate probes per array, averaged over three replicate arrays.). X-axes, position numbering on ICEclc. Middle part, representation of the gene locations in the ICEclc core region (block arrows), and the size and position of the transcripts concluded from RT-PCR and Northerns (Figure 1-3) 
Table 1: Summary of ICEclc core transcripts.

\begin{tabular}{|c|c|c|c|c|c|}
\hline Transcript & Stranda & Size on Northern ${ }^{b}$ & RT-PCRC & Promoterd & Log2 Stat-Expo Ratio \\
\hline intB13 & + & 2.5 & + & 102,729 (Pcirc) & $3.1 \pm 1.0$ \\
\hline ORF50240 & - & ND (1.8) & ND & & $1.6 \pm 0.6$ \\
\hline $52324-53196$ & + & $1.5(1.2)$ & + & 51,218 & $-1.2 \pm 0.4$ \\
\hline $53587-58432$ & - & $4.7(5.3)$ & + & 58,771 & $4.2 \pm 1.4$ \\
\hline $59110-62755$ & - & $3.5(4.0)$ & + & 63,191 & $2.6 \pm 1.3$ \\
\hline $63176-66202$ & - & $3.5(3.4)$ & + & 66,976 & $2.3 \pm 1.7$ \\
\hline $66625-67231$ & - & ND (1.0) & + & 67,610 & $5.8 \pm 2.2$ \\
\hline 67800 & + & $2.6(0.5)$ & + & 67,817 & $-0.9 \pm 0.2$ \\
\hline \multirow[t]{2}{*}{$68241-81655$} & - & $4-6$ & + & & $4.0 \pm 1.7$ \\
\hline & & $8.5(14.3)$ & (exc. 73676-74436) & & $5.7 \pm 1.6$ \\
\hline $83350-84835$ & - & $2.6(2.3)$ & + & & $6.3 \pm 1.6$ \\
\hline $85934-88400$ & - & $3.0(2.7)$ & + & 89,109 & $6.5 \pm 0.8$ \\
\hline $89247-89746$ & - & $2.5(2.1)$ & + & & $2.2 \pm 1.9$ \\
\hline $91884-95213$ & - & $3.5 / 2(4.1)$ & + & 96,204 (RACE) & $5.6 \pm 1.5$ \\
\hline $96323-100033$ & - & $2.5-3.5(4.5)$ & & & $2.1 \pm 1.6$ \\
\hline 100952 & - & 0.5 & + & & ND \\
\hline $100033-101284$ & - & $2.6(2.0)$ & + & 102,270 (RACE) & $2.0 \pm 0.2$ \\
\hline
\end{tabular}

a) plus strand is same orientation as intB13.

b) in kilobase observed; within brackets, size calculated from sequence.

c) ORF connections detected by reverse-transcriptase PCR on RNA from strain B13 during stationary phase after growth on 3-chlorobenzoate.

d) Predicted location from bioinformatic analysis or observed by 5'RACE. Position according to numbering of AJ617740.

e) Log2-average ratio of hybridization intensities over all microarray probes covering the presumed transcript during stationary phase versus

exponential phase on 3-chlorobenzoate.

tor) [26] and ORF95213 (hypothetical protein). Indeed, Northerns had already suggested two transcripts here, not completely covering the whole region (Figure 1 and 3 ), and also tiling array hybridizations showed two or even three differently 'sloped' hybridization patterns. Therefore, it might be that there is read-through from ORF94175 into ORF91884, producing the detected RTPCR connection, but an additional promoter upstream of ORF91884 does not seem unlikely (Table S1).

Whereas most of the genes in the ICEclc core region are organized on the minus strand (with respect to the intB13 gene, Figure 1), four genes are oriented on the plus strand. In general, hybridization signal intensities on micro-array for plus strand probes were lower than for the minus strand (Figure 4), but the signals coming from the small cluster of three genes at around 53,000 and the single ORF67800 can be discerned on micro-array as being significantly above local background.

\section{Carbon substrate dependent expression of ICEclc core genes}

Micro-array hybridizations clearly demonstrated that most of the core genes on the minus strand are upregu- lated in stationary phase conditions (Table 1, Figure 4), with -- fold changes ranging from $2^{2}$ (e.g., for ORF50240 or the cluster of genes between 96,000 and 100,000$)$ to $2^{7}$ (e.g., ORF81655). RNAs from a larger number of different growth conditions were hybridized in dot-blot format using digoxigenin-labeled probes representative for all proposed transcripts (Tables 2 and 3). This showed that the expression of the highly abundant core transcripts represented by ORF81655, ORF87986 and ORF84835 (Table 2) actually started in the first twelve hours after reaching stationary phase and then increased continuously further up to $72 \mathrm{~h}$. In contrast, transcription from the three plus strand ORFs 52324-53196 seemed to 'peak' in very early stationary phase, but then successively decreased (Table 2). Hybridizing blotted RNAs from $P$. knackmussii B13 grown to stationary phase on different carbon substrates showed, interestingly, that the three transcripts 68241-81655 (represented by probes 7, 8, 9 and 10), 83350-84835 (probes 11 and 12), and 8593488400 (probe 13) were highly induced only in stationary phase cells that had been cultured with 3-chlorobenzoate or fructose, but not at all with succinate or glucose (Table $3)$. Highest induction of the ICEclc core region genes in 
Table 2: ICEclc core gene transcript abundance in P. knackmussii B13 cultures grown with 3-chlorobenzoate as a function of growth phase as quantified by macroblot hybridization.

\begin{tabular}{|c|c|c|c|c|c|c|c|c|c|c|c|c|c|c|c|}
\hline \multirow[b]{2}{*}{ Probes } & \multirow[b]{2}{*}{ Probe number } & \multicolumn{2}{|c|}{ expo } & \multicolumn{2}{|c|}{ e-stat } & \multicolumn{2}{|c|}{$12 \mathrm{~h}$} & \multicolumn{2}{|c|}{$24 h$} & \multicolumn{2}{|c|}{$36 \mathrm{~h}$} & \multicolumn{2}{|c|}{$48 h$} & \multicolumn{2}{|c|}{$72 \mathrm{~h}$} \\
\hline & & mRNAa & $\begin{array}{c}\text { Std Devb } \\
(\%)\end{array}$ & mRNA & $\begin{array}{c}\text { Std Dev } \\
\text { (\%) }\end{array}$ & mRNA & $\begin{array}{c}\text { Std Dev } \\
\text { (\%) }\end{array}$ & mRNA & $\begin{array}{c}\text { Std Dev } \\
\text { (\%) }\end{array}$ & mRNA & $\begin{array}{c}\text { Std Dev } \\
(\%)\end{array}$ & mRNA & $\begin{array}{c}\text { Std Dev } \\
\text { (\%) }\end{array}$ & mRNA & $\begin{array}{c}\text { Std Dev } \\
\text { (\%) }\end{array}$ \\
\hline intB13 & 1 & 4.5 & 11.2 & 4.3 & 12.9 & 4.6 & 15.6 & 5.1 & 28.5 & 3.2 & 5.3 & 3.4 & 0.9 & 3.5 & 14.6 \\
\hline ORF52710 & 2 & 21.3 & 46.5 & 29.6 & 8.7 & 17.8 & 3.4 & 9.3 & 39.9 & 7.8 & 53.8 & 12.6 & 18.6 & 6.4 & 41.8 \\
\hline ORF53587 & 3 & 4.2 & 30.2 & 2.9 & 25.9 & 2.6 & 27.1 & 1.7 & 37.3 & 3.4 & 11.9 & 3.1 & 20.4 & 1.4 & 12.2 \\
\hline ORF59888 & 4 & 18.6 & 33 & 20 & 7.5 & 14.7 & 18.9 & 8.4 & 32.3 & 16.8 & 23.9 & 22.4 & 9.3 & 14.6 & 43.4 \\
\hline ORF65513 & 5 & 17.3 & 19.4 & 17.1 & 0.8 & 16.7 & 10.3 & 13.4 & 9.9 & 11.8 & 9.5 & 13.5 & 2.4 & 12.4 & 10.7 \\
\hline ORF67800 & 6 & 16.6 & 2.7 & 12.4 & 26.1 & 10.1 & 11.6 & 8 & 12.9 & 14.6 & 4.3 & 12.6 & 10.7 & 8.5 & 16.6 \\
\hline ORF68987c & 7 & 2.1 & 4.3 & 1.7 & 8.2 & 1.2 & 30.1 & 0.8 & 12.9 & 1.7 & 6.5 & 1.5 & 4.3 & 1 & 22.3 \\
\hline ORF73029 & 8 & 2.5 & 20.8 & 1.4 & 15 & 2.1 & 18.5 & 2.6 & 15 & 2 & 14.6 & 2.2 & 2.3 & 1.5 & 10.4 \\
\hline ORF75419 & 9 & 7.5 & 18.1 & 4.5 & 7.6 & 8.7 & 0.4 & 11.1 & 32 & 14 & 27.1 & 20.5 & 9.4 & 28 & 31.6 \\
\hline ORF81655 & 10 & 10.2 & 30.1 & 6.4 & 35.8 & 104 & 4.8 & 168 & 24.5 & 113 & 24.3 & 191 & 14.5 & 177 & 10.9 \\
\hline ORF83350 & 11 & 3.3 & 18.9 & 1.7 & 7 & 0.9 & 17.8 & 0.9 & 26.1 & 0.9 & 3.5 & 0.9 & 5 & 0.9 & 5.6 \\
\hline ORF84835 & 12 & 0.4 & 14.4 & 0.3 & 38.3 & 7.4 & 53.2 & 9.5 & 7.7 & 20.6 & 28.9 & 28.1 & 29.5 & 29.8 & 22.8 \\
\hline ORF87986 & 13 & 5 & 1 & 4.6 & 39.3 & 41.1 & 16.1 & 64.5 & 7.2 & 41.3 & 12.9 & 54.9 & 22.1 & 100 & 11.5 \\
\hline ORF89746 & 14 & 12.9 & 34.1 & 12.9 & 10.4 & 4.9 & 12 & 2.2 & 41.2 & 1.3 & 44.9 & 3.4 & 28.9 & 3.2 & 19.8 \\
\hline ORF91884 & 15 & 3.3 & 11.7 & 2.1 & 25.6 & 2.4 & 14.7 & 3 & 32.4 & 3.1 & 14 & 3.2 & 11.3 & 4.1 & 5.2 \\
\hline $\operatorname{inr} R$ & 16 & 8.3 & 11.9 & 6.4 & 10.5 & 7.4 & 13.1 & 4.5 & 11.6 & 5.1 & 18.8 & 7.2 & 0.6 & 5.9 & 12 \\
\hline ORF96323 & 17 & 3 & 13 & 1.7 & 13.3 & 1.1 & 5.5 & 1 & 2.8 & 1.3 & 12.8 & 1.1 & 14.4 & 1.2 & 13.2 \\
\hline ORF98147 & 18 & 1.1 & 10.7 & 0.5 & 14.2 & 0.4 & 4.6 & 0.5 & 5.9 & 0.5 & 8.3 & 0.4 & 2.4 & 0.4 & 0.9 \\
\hline ORF100033 & 19 & 30.6 & 4 & 23 & 4.3 & 26 & 8.7 & 12.3 & 16.7 & 19.6 & 14.3 & 20.4 & 22.4 & 21.5 & 16.3 \\
\hline ORF100952 & 20 & 1.4 & 13.2 & 3.7 & 31.2 & 2.8 & 4.9 & 1.8 & 3.1 & 1.7 & 58.5 & 3.5 & 30.8 & 6.7 & 13.4 \\
\hline ORF101284 & 21 & 3.7 & 18.9 & 4.5 & 10.1 & 2.1 & 5.8 & 1 & 23.1 & 1.9 & 9.7 & 1.5 & 11 & 1.3 & 11.5 \\
\hline
\end{tabular}


Table 3: Quantification of ICEclc core gene expression by dot-blot hybridization in strain B13 grown on different carbon substrates.

\begin{tabular}{|c|c|c|c|c|c|c|c|c|c|c|c|c|}
\hline \multirow{4}{*}{$\begin{array}{l}\text { Probe } \\
\text { number } \\
\text { and probe }\end{array}$} & \multicolumn{4}{|c|}{ Exponential phase } & \multicolumn{8}{|c|}{ After $24 \mathrm{~h}$ at stationary phase } \\
\hline & \multicolumn{2}{|c|}{ 3-chlorobenzoate } & \multicolumn{2}{|c|}{ succinate } & \multicolumn{2}{|c|}{ 3-chlorobenzoate } & \multicolumn{2}{|c|}{ succinate } & \multicolumn{2}{|c|}{ fructose } & \multicolumn{2}{|c|}{ glucose } \\
\hline & mRNA $^{a}$ & $\begin{array}{c}\text { Std } \\
\text { Dev }^{\mathbf{b}}\end{array}$ & mRNA & $\begin{array}{l}\text { Std } \\
\text { Dev }\end{array}$ & mRNA & Std Dev & mRNA & Std Dev & mRNA & Std Dev & mRNA & Std Dev \\
\hline & & $(\%)$ & & (\%) & & (\%) & & (\%) & & (\%) & & (\%) \\
\hline 1) intB13 & 4.5 & 11.2 & 7.3 & 13.1 & 5.1 & 28.5 & 4.1 & 11.2 & 4.4 & 51.7 & 3.2 & 8.1 \\
\hline 2) ORF52710 & 21.3 & 46.5 & 19.7 & 16.9 & 9.3 & 39.9 & 9.6 & 8 & 5.1 & 42.7 & 9.4 & 30.6 \\
\hline 3) ORF53587 & 4.2 & 30.2 & 3.6 & 0.1 & 1.7 & 37.3 & 1.7 & 21.1 & 2 & 0.4 & 1.9 & 2.6 \\
\hline 4) ORF59888 & 18.6 & 33 & 16.9 & 2.3 & 8.4 & 32.3 & 12.9 & 18.6 & 16.8 & 7.3 & 23.8 & 15.9 \\
\hline 5) ORF65513 & 17.3 & 19.4 & 19.5 & 2.8 & 13.4 & 9.9 & $12.7^{\ddagger}$ & 5.3 & 13.8 & 7.6 & 13.8 & 11 \\
\hline 6) ORF67800 & 16.6 & 2.7 & 16.6 & 5.5 & 8 & 12.9 & 12.7 & 18.3 & 11.6 & 33.7 & 17.9 & 38.6 \\
\hline 7) ORF68987 & 2.1 & 4.3 & 2.1 & 11 & 0.8 & 12.9 & 0.8 & 0.2 & 1.3 & 13.8 & 1.1 & 11.7 \\
\hline 8) ORF73029 & 2.5 & 20.8 & 2.9 & 12.6 & $2.6^{*}$ & 15 & $0.9^{\ddagger}$ & 18.2 & 1.4 & 6.7 & 1.1 & 4.2 \\
\hline 9) ORF75419 & 7.5 & 18.1 & 7.3 & 6.8 & 11.1 & 32 & $3^{\ddagger}$ & 3.9 & 3.9 & 3.3 & 2.8 & 5.4 \\
\hline 10) ORF81655 & 10.2 & 30.1 & 18.7 & 36.6 & $168^{*}$ & 24.5 & 6.3 & 2.7 & $45.7^{*}$ & 3.6 & 9.2 & 27 \\
\hline 11) ORF83350 & 3.3 & 18.9 & 2.8 & 16.5 & 0.9 & 26.1 & 0.5 & 37.3 & 0.5 & 14.5 & 0.4 & 10.2 \\
\hline 12) ORF84835 & 0.4 & 14.4 & 0.3 & 16.3 & 9.5* & 7.7 & 0.3 & 25.8 & 1.7 & 16.1 & 0.3 & 1.5 \\
\hline 13) ORF87986 & 5 & 1 & 5.2 & 0.1 & $64.5^{*}$ & 7.2 & $5.5^{\ddagger}$ & 0.4 & 14.2 & 26.9 & 5.5 & 2 \\
\hline 14) ORF89746 & 12.9 & 34.1 & 24.4 & 19.8 & 2.2 & 41.2 & 2.1 & 17.3 & 2.1 & 36.7 & 0.5 & 15.4 \\
\hline 15) ORF91884 & 3.3 & 11.7 & 4.5 & 3 & 3 & 32.4 & $1.6^{\ddagger}$ & 3.2 & 2.3 & 33.1 & 1.1 & 5.9 \\
\hline 16) $i n r R$ & 8.3 & 11.9 & 8.2 & 21.3 & 4.5 & 11.6 & 4 & 7.5 & 6.4 & 8.1 & 4.9 & 39.7 \\
\hline 17) ORF96323 & 3 & 13 & 5.3 & 27.1 & 1 & 2.8 & 1.8 & 35.6 & 0.9 & 53.2 & 1.1 & 31.8 \\
\hline 18) ORF98147 & 1.1 & 10.7 & 1.5 & 5.1 & 0.5 & 5.9 & $0.4^{\ddagger}$ & 7 & 0.4 & 3.7 & 0.4 & 1.7 \\
\hline 19) ORF100033 & 30.6 & 4 & 40.4 & 20.2 & 12.3 & 16.7 & 17.6 & 18 & 22.9 & 6.4 & 22.2 & 30.2 \\
\hline 20) ORF100952 & 1.4 & 13.2 & 2.2 & 22.2 & $1.8^{\S}$ & 3.1 & 0.9 & 1.7 & 1.9 & 7.9 & 0.9 & 29.4 \\
\hline 21) ORF101284 & 3.7 & 18.9 & 3.2 & 6.9 & 1 & 23.1 & $1^{\neq}$ & 7.9 & 1.1 & 1.9 & 1.2 & 14.5 \\
\hline
\end{tabular}

a) mRNA is the average calculated amount of mRNA copies $\times 10^{8}$ per $\mu \mathrm{g}$ of total RNA from triplicate determinations. This value corresponds approximately to the calculated number of mRNA of this transcript per cell.

b) standard deviation from the average mRNA, expressed in percentage.

c) ${ }^{*}$, values statistically significantly different to the cells cultivated with other carbon sources. ${ }^{\S}$, values statistically significantly different to the cells cultivated with succinate or glucose. $\neq$, values statistically significantly different between exponential phase and stationary phase. $\mathrm{P} \leq 0.05$ in pairwise Student's T test.

stationary phase cells grown with 3-chlorobenzoate is in agreement with previous experiments that showed the highest proportion of excised ICE $c l c$ and highest ICEclc transfer rates in cells cultured on 3-chlorobenzoate to stationary phase $[26,27]$.

Another gene that produced relatively high signals in dot-blot hybridizations was ORF100033, which urged us to analyze its expression more conspicuously by RT-PCR. Contrary to RNA isolated in stationary phase from 3chlorobenzoate or fructose-grown cultures, consistently no RT-PCR product was obtained for the intergenic region between ORF100952 and ORF101284 on RNA from cells that had been cultivated with glucose (Figure 5, panels $\mathrm{d}$ and e). RNA isolated from all three substrate conditions did produce a smaller RT-PCR fragment directly upstream of ORF100952 (Figure 5B panel b), suggesting that an additional promoter exists that produces a transcript covering ORF100952 only. In fact, Northern hybridizations with a probe for ORF100952 produced an additional band of $0.5 \mathrm{~kb}$ length (Figure 3 ). The promoter located in front of ORF101284 might thus be specifically repressed after growth on glucose (and perhaps succi- 


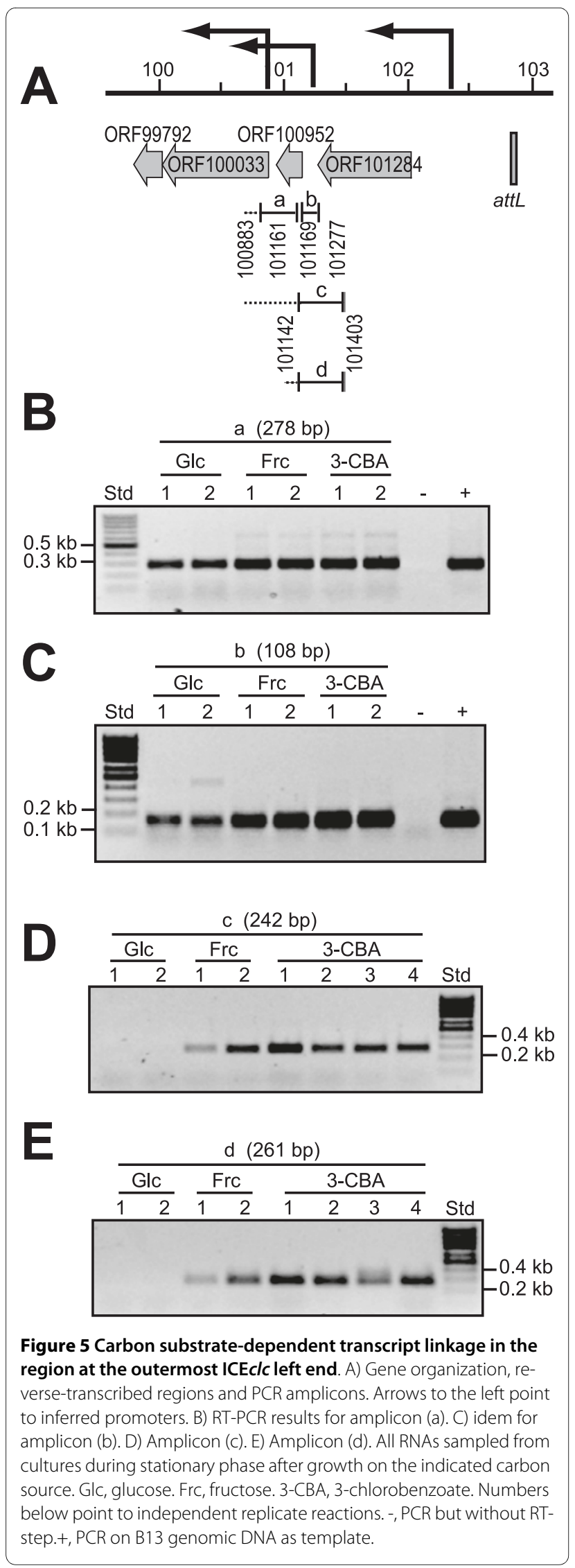

nate), or specifically activated after growth on 3-chlorobenzoate and fructose.

\section{Promoter analysis}

Results from 5'-RACE were not as conclusive as expected. Although various amplicons were produced from cDNA ends, only few matched the start region for transcripts detected by RT-PCR, Northern and micro-array. In contrast, the start site for the transcript covering inrR could be mapped in the region upstream of ORF95213 to a thymine located $25 \mathrm{nt}$ upstream of the ORF95213 start codon. Interestingly, the corresponding -10 box (TGTCGATCCT) and -35 (TTGACT) are close to the proposed consensus sequence of $\sigma^{5}$ and not $\sigma^{70}$, suggesting it is controlled by RpoS [26]. This could explain a higher abundance of this transcript during stationary compared to exponential phase as seen on micro-array (Figure 4). 5'RACE also produced a clear transcription start upstream of ORF101284 (position 102,270), which is in agreement to the other data and suggests a promoter being present at positions 102,283 to 102,288 (-10, TATTAC) and 102,300 to 102,305 (-35 region, TTGCAG). On the contrary, no 5'RACE product but a very weak product was obtained by primer extension in the region upstream of ORF81655, which located at $\sim 250$ bp upstream of the start codon (results not shown), even though this transcript was among the most abundant ones of the ICEclc core region (Figure 4). In a few other cases, bioinformatic searches identified promoter signatures which locate in regions where transcripts were deemed to start (Table 1, S1), but their nature remains to be experimentally verified.

\section{Discussion}

By using a combination of semi-tiling micro-array hybridization and conventional techniques for transcription analysis, we obtained a highly detailed picture on the transcriptional organization of the ICEclc core region. To our knowledge, this is one of the first examples of tiling micro-array in combination with RT-PCR and Northern hybridizations to study transcriptional organization of mobile DNA elements, the only other one currently being a study on the plasmid pCAR1 of $P$. resinovorans [29]. We conclude from our results that such a combined approach can give excellent complementary data and retrieve details that either one of the typical transcription approaches alone cannot obtain. Except for a few locations, the results from all approaches on ICEclc's transcriptome were mostly in agreement with each other, or critically supported omissions in each of them individually. Fourteen transcripts were detected by RT-PCR and Northern; one more was inferred from micro-array hybridization (ORF50240). Some transcripts seem clearly part of one larger but rapidly cleaved polycistronic mRNA (e.g, ORF68241-81655), whereas in one case 
(ORF59110-67231) three transcripts were consistently detected but gene organization suggests close linkage.

The importance of the ICEclc core gene region lays in its proposed control of the element's behavior: excision, self-transfer, maintenance and reintegration. Even though still only few ICEclc core genes have clear identifiable homology to known proteins (Additional file 1, Table S1), the region as a whole is largely conserved in a large collection of other GEI, underscoring its functional importance for life-style [23,24]. The 14 or 15 transcripts in the ICEclc core region, including a long $14.5 \mathrm{~kb}$ transcript (Figure 1,4), is in the order of transcript numbers typically found for self-transfer and maintenance functions of conjugative plasmids (e.g., eight for R27 in E. coli [30], 14 for pCAR1 in P. resinovorans [29]). Four of the core transcripts (between ORF53587 and ORF73676) might code for a type IV secretion system (mating pair formation complex) similar to that of ICEHin1056 from $\mathrm{H}$. influenza (Figure 6, Additional file 1, Table S1) [16]. Furthermore, the ORF50240 product has weak homology to a relaxase and ORF91884 has a DNA topoisomerase domain, suggesting possible implication in a relaxosome complex involving the excised circular ICEclc form (Additional file 1, Table S1). A comparison with the ICEHin1056 transcriptional organization in this area shows a number of differences, which are likely due to extensive gene arrangements during evolutionary divergence between the two elements (Figure 6). For example, the long ICEHin 1056 transcript covering the mating pair complex (PilL, TraB, TraD etc.), is interrupted on ICEclc by the reversely oriented ORF67800. The transcript containing ORF73676 (the presumed pilL) is not the start, but part of a much longer transcript starting at ORF81655 on ICEclc. Second difference between ICEclc and ICEHin1056 relates to the large inversion of the genes $t f c 21$ to $t f c 24$ (Figure 6). ICEHin1056 data suggested two transcripts in this region, with one being formed by the presumed regulatory gene $t f c 24$ [16]. In contrast, on ICEclc ORF57827 (the homologue of $t f c 24$ on ICEclc, Figure 6) is apparently the second gene of a six-gene transcript.

The relative abundance of transcripts in the region ORF50240 to ORF81655 of ICEclc was up to 64-fold (microarray) different between stationary and exponential phase (Figure 2 and 3, Table 1). If the postulate is correct that these genes would encode part of the type IV secretion system necessary for ICEclc transfer (i.e., the equivalent of the Mating Pair Formation or mpf complex in conjugative plasmids [6]), their induction would be much more pronounced than what is usual for plasmid conjugative systems. In most cases, the $m p f$ genes are either weakly expressed or tightly regulated and inducible [6], the reason presumably being that expression of the conjugative apparatus is energy costly and could favor male-type specific phage infection. Tight control of the transfer genes of plasmids is often achieved by autoregulatory loops, such as the IncP-9 pWW0 plasmid traA and $m p f R$ genes that control the relaxosome complex and $m p f$ operons, respectively [31]. Also, the presumed genes involved in conjugative transfer of the IncP-7 plasmid pCAR1 in Pseudomonas putida and P. resinovorans are expressed at low and similar transcriptional level (without further specification) during growth on succinate or carbazole [29]. Induction of the putative conjugative system of ICEclc would thus be more similar to the type of induction found in the SXT element [18], which is a hybrid between phage-lambda type control and plasmidlike conjugation. However, none of the ICEclc functions has any significant sequence similarity to the SetR -- SetC -- SetD regulators of SXT, nor to the CI repressor from $\lambda$. The type of program that seems to be followed by ICEclc (integrase induction, excision, and global response of the core region) is indeed reminiscent of a phage program [9], but we conclude that control layers are different from

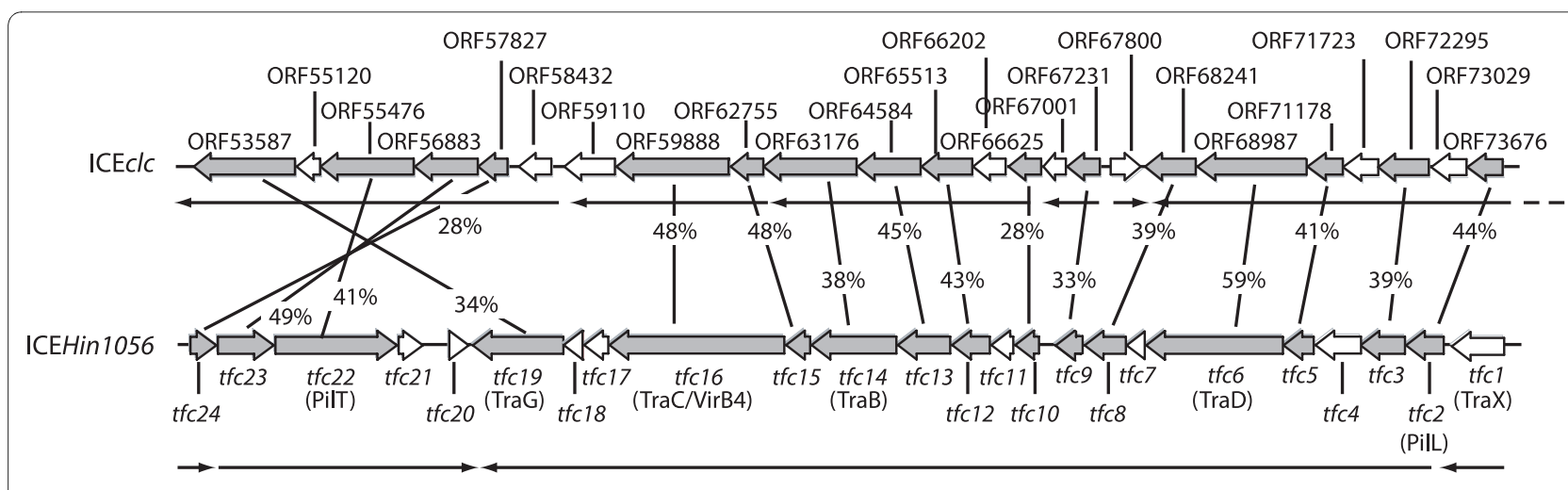

Figure 6 Comparison of the tfc-like gene region on ICEclc with ICEHin 1056 from $\mathbf{H}$. influenzae. Lines indicate percentage amino acid similarity between common genes (grey-shaded). Genes indicated in open arrows have no significant homologies among the two ICE. Arrows underneath point to the transcriptional organization in this region. Data on ICEHin1056 redrawn from [16]. 
phage type. The finding that basically eight of fifteen identified transcripts in the ICEclc core region are upregulated during stationary phase, suggests a coordinated global control mechanism, which is perhaps assisted by the stationary phase sigma factor RpoS. Indeed, some evidence for RpoS control was obtained from sequence motifs in the inrR promoter. It is interesting to speculate as to what would be the ecological or physiological advantage for ICEclc to become active during stationary phase. One hypothesis is that of the 'sinking ship': the element senses that its host survival (and therefore that of itself) is endangered and tries to escape to a more favorable host cell (even though this must be in its immediate vicinity). Even more intriguing is perhaps the carbon substrate-specific upregulation of ICEclc activity, which is highest after growth on 3-chlorobenzoate, less with fructose and very low with glucose or succinate as carbon sources. Upregulation of the ICEclc core region expression in stationary phase cells grown with 3-chlorobenzoate is in agreement with previous results showing increased activity of the integrase promoter [26], increased proportion of ICEclc excised DNA and increased ICEclc transfer rates [27]. Since it is assumed that during stationary phase cells have depleted their carbon source, the carbon source can no longer be directly be responsible for the activation, but somehow must have generated a 'memory' effect which triggers ICEclc response. In this light, the repression seen for transcription read-through from ORF101284 with glucose and succinate might point to a Crc-type regulation of catabolite repression in Pseudomonas [32,33], although for the time being no specific $\mathrm{Crc}$ binding motifs were detected in the ICEclc core region.

\section{Conclusions}

In conclusion, we have identified fifteen transcripts covering the presumed core region for behavioral functions of ICEclc. Eight of those are concertedly upregulated during stationary phase, but only after previous growth of the cells on 3-chlorobenzoate or fructose, which explains previous results that have seen highest ICEclc transfer rates under such conditions [27]. The number and lengths of ICEclc transcripts is similar to that found for typical conjugative plasmid systems, yet the mode of global transcription control is more reminiscent for phage-type control. We thus conclude that the hybrid transcriptional control mode comprising both conjugative plasmid and phage strategies has been selected in mobile elements of the ICEclc group.

\section{Methods}

\section{Growth conditions and harvesting}

P. knackmussii B13, the original host of ICEclc, was cultivated in minimal medium (MM) based on the type $21 \mathrm{C}$ medium [34]. This MM was complemented with 3-chlorobenzoate, fructose, glucose (all at $10 \mathrm{mM}$ ) or $15 \mathrm{mM}$ succinate, and the bacteria were grown at $30^{\circ} \mathrm{C}$. Bacterial growth was assessed from culture turbidity at $600 \mathrm{~nm}$ $\left(\mathrm{OD}_{600}\right)$. Cells were recovered during exponential phase $\left(\mathrm{OD}_{600}\right.$ of 0.4$)$ or early stationary phase $\left(\mathrm{OD}_{600}=1.2\right)$, which was defined as the point where growth began to cease plus one period equivalent to the shortest generation time on that substrate. Bacteria were also recovered $12,24,36,48$ or $72 \mathrm{~h}$ after the beginning of the stationary phase. For RNA isolation, $100 \mathrm{ml}$ of culture was immediately harvested by centrifugation (at 15,000 $\times g$ for $1 \mathrm{~min}$ at $4^{\circ} \mathrm{C}$ ) and the supernatant was decanted. Cell pellets were resuspended in $4 \mathrm{ml}$ RNAprotect Bacteria Reagent (QIAGEN GmbH). After 5 min incubation, the suspensions were centrifuged again (at 5,000 $\times g$ for $5 \mathrm{~min}$ at room temperature); the supernatant was discarded and pellets were stored at $-80^{\circ} \mathrm{C}$.

\section{RNA isolation}

Prior to RNA extraction, pellets were slowly thawed, then resuspended in $0.5 \mathrm{ml}$ TES buffer $[10 \mathrm{mM}$ Tris- $\mathrm{HCl}(\mathrm{pH}$ 8.0), $1 \mathrm{mM}$ EDTA, $100 \mathrm{mM} \mathrm{NaCl}$, followed by addition of and mixing with $0.25 \mathrm{ml}$ lysis solution [ $20 \mathrm{mM}$ sodium acetate (pH 5.5), $1 \mathrm{mM}$ EDTA, 0.5\% SDS]. After that, the total RNA was further purified by the hot acid-phenol method as described previously [35]. RNA samples were purified from contaminating DNA by treatment with 50 $\mathrm{U}$ of DNase I (RNase free; Roche) during $1 \mathrm{~h}$ at $37^{\circ} \mathrm{C}$. Finally, the RNA was dissolved in $50 \mu \mathrm{l}$ diethylpyrocarbonate (DEPC)-treated water and quantified by absorbance at 260 and $280 \mathrm{~nm}$ on a NanoDrop spectrophotometer (Witec AG). The integrity of RNA was determined by agarose gel electrophoresis and the absence of DNA was verified by PCR.

\section{Reverse transcription PCR (RT-PCR)}

Reverse transcription was made on RNA isolated from cultures grown with 3-chlorobenzoate, glucose or fructose, and harvested $24 \mathrm{~h}$ after the beginning of stationary phase. $0.5 \mu \mathrm{g}$ of total RNA was denatured by heating at $65^{\circ} \mathrm{C}$ and reverse transcribed using the Omniscript RT kit (QIAGEN GmbH) following the instructions of the manufacturer, using primers listed in Additional file 1, Table S2. Primer designations refer to their exact position on ICEclc according to the numbering in AJ617740 (Genbank Accession number). 30 cycles of PCR amplification with the produced cDNA templates was performed with the HotStarTaq Master Mix kit (QIAGEN GmbH), using one tenth of volume from the reverse transcription reaction and $10 \mu \mathrm{M}$ of a pair of specific primers (Additional file 1, Table S2). Amplification of regions between ORF94175 and inrR known to be co-transcribed served as positive control for the quality of the RT-PCR reaction. 
Finally, for each RNA sample, a PCR was performed without reverse transcriptase step, in order to control for the absence of DNA contamination.

\section{Mapping of transcriptional start sites}

The $5^{\prime}$ end of the transcript including inrR was mapped with the SMART RACE cDNA Amplification Kit (Clontech Laboratories, Inc.) according to the manufacturer's protocol. cDNA was synthesized from $0.5 \mu \mathrm{g}$ RNA with the primer 95,129rv, which is located within the inrR region. After generation of RACE-Ready CDNA, a PCR and a nested PCR were performed by using the inrR-specific primer 95,156rv plus the Universal Primer A (UPM, Clontech), and the inrR primer 95,677rv plus the Nested Universal Primer A (NUP), respectively. Both PCR products were sequenced using a further inrR specific primer 95,790rv in the BigDye Terminator v3.1 cycle sequencing kit (Applied Biosystems), and were separated on ABI PRISM 3100 Genetic Analyzer (Applied Biosystems). A further successful mapping was deployed with 5'RACE on the transcript starting upstream of the most distal ICEclc ORF101284. 5'RACE reactions for the regions upstream of ORFs 58432, 66202, 73676, 81655, 88400, and 89746 did not produce specific fragments.

\section{Digoxigenin-labeled probe synthesis}

DNA regions of between 126 and 560 bp of 21 selected ORFs from the $c l c$ element's core region (Figure 1) were amplified by PCR for probe synthesis (Additional file 1, Table S3). One of the PCR primers (reverse complementary to the targeted ORF) included the sequence for the promoter region of T7 RNA polymerase. Antisense digoxigenin-labeled RNA probes were then synthesized from $\sim 1 \mu \mathrm{g}$ of purified PCR product by using T7 RNA polymerase according to instructions of the suppliers (Roche Applied Science).

\section{Northern hybridization}

$20 \mu \mathrm{g}$ of total RNA were incubated in $20 \mu \mathrm{l}$ (total volume) of denaturation buffer (containing $1 \mathrm{M}$ glyoxal, 25\% v/v dimethylsulfoxide, $10 \mathrm{mM}$ sodium phosphate, $\mathrm{pH}$ 7.0) for $1 \mathrm{~h}$ at $50^{\circ} \mathrm{C} .100 \mathrm{ng}$ of a digoxigenin-labeled RNA molecular weight marker I (0.3 -- $6.9 \mathrm{~kb}$, Roche Diagnostics) was treated similarly. A volume of $0.2 \mu \mathrm{l}$ of a $10 \mathrm{mg} / \mathrm{ml}$ ethidium bromide solution and $1 \mu$ loading buffer (containing $50 \%$ sucrose, $15 \mathrm{mg} / \mathrm{ml}$ bromophenol blue in DEPCtreated $\mathrm{H}_{2} \mathrm{O}$ ) were added to the samples at the end of the incubation period and mixed. Fragments were separated at $50 \mathrm{~V}$ on a $1 \%$ agarose gel in $10 \mathrm{mM}$ sodium phosphate buffer (pH 7.0). RNA was subsequently transferred from gel onto Hybond $\mathrm{N}^{+}$nylon membrane (Amersham Biosciences) in $10 \times$ concentrated SSC solution (containing $3 \mathrm{M}$ $\mathrm{NaCl}$ and $0.3 \mathrm{M}$ sodium citrate dissolved in demineralized $\mathrm{H}_{2} \mathrm{O}$ ) with the help of the VacuGene XL system
(Amersham Biosciences) for $3.5 \mathrm{~h}$ at a vacuum of 50 mbar. After transfer, RNA was fixed to the membrane with a UV crosslinker (CX-2000, UVP) at a dose of $0.3 \mathrm{~J}$ per $\mathrm{cm}^{2}$. Immediately before hybridization, the membrane was rinsed with $20 \mathrm{mM}$ Tris $-\mathrm{HCl}(\mathrm{pH} 8.0)$ at $65^{\circ} \mathrm{C}$ for $10 \mathrm{~min}$ to remove glyoxal. The hybridization was performed in DIG Hybridization buffer (Roche Diagnostics) for $15 \mathrm{~h}$ at $68^{\circ} \mathrm{C}$. The washing steps and the immunochemiluminescent detection were done according to the supplier's instructions (Roche Diagnostics) using alkaline-phosphatase-conjugated anti-digoxigenin Fab fragments and CSPD as reagent for the chemiluminescence reaction. Light emission was detected on Hyperfilm ECL (Amersham Biosciences).

\section{Dot blot hybridization and relative mRNA quantification}

Total RNA extracted from different growth phases and substrates were further analyzed for expression of genes from the core region of ICEclc in 96-well format dot-blot hybridization. RNA was isolated from three independent cultures of strain B13 grown with 3-chlorobenzoate at exponential phase, early-stationary phase, as well as at 12 , 24, 36, 48 and $72 \mathrm{~h}$ after the beginning of stationary phase. Furthermore, duplicate cultures of B13 grown with glucose, fructose and succinate harvested after $24 \mathrm{~h}$, and duplicate cultures grown on succinate in exponential phase were used for RNA purification as well. $15 \mu \mathrm{l} \mathrm{Ali-}$ quots of dilutions containing $1,0.3$, and $0.1 \mu \mathrm{g}$ denatured total RNA were dot-blotted using a 96-well manifold (Gibco Life Technologies) onto positively charged nylon transfer membranes (Hybond- $\mathrm{N}^{+}$, Amersham Biosciences AG). Different concentrations of denatured PCR products $(2.5,1,0.5,0.25,0.1,0.05,0.025$ and $0.01 \mathrm{ng})$ comprising the respective targeted ORF were included on the same blot. RNA was fixed to the membrane with a UV crosslinker before hybridization as described above. Films were scanned and spot intensities were calculated by densitometry using the Image Quant TL program (v2005, Molecular Dynamics, Sunnyville, USA) as grey intensity per standardized surface. The signal intensity of each spot was then compared to the standard curve of DNA dilutions on the same blot to calculate an 'equivalent number of DNA copies', and divided by the total amount of RNA in the spot to normalize to a value of 'equivalent number of copies per $\mu \mathrm{g}$ RNA'.

\section{Microarray design}

A series of 950 non-overlapping 50-mer probes was designed to cover both coding and non-coding regions of the ICEclc sequence (Acc. No. AJ617740) at approximate distances of $200 \mathrm{bp}$. Probes were designed using the program OLIGOARRAY version 2.1 [36] with a melting temperature range of 92 to $99^{\circ} \mathrm{C}$ and a probe GC content range of 52 to $72 \%$. Probes were further designed to not cross- 
hybridize with gene products from the following potential host strains of the ICEclc element: Burkholderia xenovorans LB400 (Acc. No. CP000270-CP000272), P. putida F1 (Acc. No. CP000712), P. putida KT2440 (Acc. No. AE015451), P. aeruginosa PAO1 (Acc. No. AE004091), Cupriavidus necator JMP134 (Acc. No. CP000090CP000093), and Ralstonia metallidurans CH34 (Acc. No. CP000352-CP000355). An additional 93 probes were designed to target housekeeping genes from the potential host strains and 8 probes were designed to target positive/negative controls (GFP, luciferase, and mCherry [37] transcripts). The microarray was manufactured by Agilent Technologies (Santa Clara, CA) in the $8 \times 15,000$ probe format and each unique probe was synthesized at six randomized spatial locations on the array. The microarray design has been deposited in the NCBI Gene Expression Omnibus http://www.ncbi.nlm.nih.gov/geo under accession number GSE20461.

\section{Microarray hybridization and analysis}

Total RNA was isolated and purified from P. knackmussii B13 cultures during exponential growth on 3-chlorobenzoate and during subsequent stationary phase after $24 \mathrm{~h}$ as described above. For microarray hybridizations, cDNA was synthesized from total RNA and directly labeled with cyanine-3-dCTP using a modification of a protocol described elsewhere [38]. Briefly, each $50-\mu \mathrm{L}$ reaction contained $10 \mu \mathrm{g}$ of total RNA, $1.25 \mu \mathrm{g}$ of random hexanucleotide primers (Promega), $100 \mu \mathrm{M}$ each of unlabeled dATP, dGTP, and dTTP (Invitrogen), $25 \mu \mathrm{M}$ of unlabeled dCTP (Invitrogen), $25 \mu \mathrm{M}$ of cyanine-3-labeled dCTP (Perkin-Elmer), $25 \mathrm{U}$ SUPERase.In (Ambion), and $400 \mathrm{U}$ Superscript II reverse transcriptase (Invitrogen). Reactions were performed by heating at $42^{\circ} \mathrm{C}$ for 2 hours followed by $70^{\circ} \mathrm{C}$ for $10 \mathrm{~min}$. RNA was then removed by adding $100 \mathrm{mM} \mathrm{NaOH}$, heating to $65^{\circ} \mathrm{C}$ for $20 \mathrm{~min}$, and neutralizing with $100 \mathrm{mM} \mathrm{HCl}$ and $300 \mathrm{mM}$ sodium acetate $(\mathrm{pH}$ 5.2). Labeled cDNA products were purified using the MinElute PCR purification kit (Qiagen) and the quantity and incorporation frequency of cyanine-3labeled dCTP were calculated using the MICROARRAY function on a NanoDrop Spectrophotometer. Sixty ng of labeled cDNA was then loaded onto each microarray, hybridized for 17 hours at $65^{\circ} \mathrm{C}$, and washed and scanned as described for labeled cRNA in the One-Color Microarray-Based Gene Expression Analysis Manual (Agilent). The fragmentation step (heating to $60^{\circ} \mathrm{C}$ for 30 minutes) was omitted.

Hybridization signal intensities were quantified from microarray image scans using AGILENT FEATURE EXTRACTION software version 9.5.3 (Agilent). Microarray data were normalized and globally scaled over the array using GENESPRING GX software with the RMA algorithm and quantile normalization $[39,40]$. Mean probe signals were calculated for each of the three biological replicates and were plotted against their position on the ICEclc sequence for both strands and for RNAs isolated during exponential and stationary phases. All microarray data have been deposited in the NCBI Gene Expression Omnibus http://www.ncbi.nlm.nih.gov/geo under accession number GSE20461.

\section{Bioinformatic tools}

Putative promoters, terminators and transcription factor binding sites were predicted by using the BPROM and FindTerm programs on http://www.Softberry.com. The map of ICEclc was designed from SeqBuilder of the Lasergene software package (version 6.1.4, DNASTAR, Inc).

\section{Additional material}

Additional file 1 Supplementary tables. Location of ORFs in the ICECIC core region and bioinformatic predictions of protein function and transcription features. Primers used in this study. Probes produced for Northern hybridizations

\section{Authors' contributions}

MG designed and performed transcription analysis. NP and MM performed microarray experiments. DJ designed probes for microarray and developed labeling and hybridization protocol. MG and VS carried out 5'RACE analysis. JvdM designed experiments and wrote the manuscript. All authors read and approved the final manuscript.

\section{Acknowledgements}

The work of MG, MM and JvdM was supported by grants 3100A-108199 and 3100-67229 from the Swiss National Science Foundation. NP is supported by a fellowship from the Faculty of Biology and Medicin of the University of Lausanne.

\section{Author Details}

'Department of Fundamental Microbiology, University of Lausanne, Bâtiment Biophore, Quartier UNI-Sorge, 1015 Lausanne, Switzerland and 2Current Address: Institute of Biogeochemistry and Pollutant Dynamics, ETHZ, Zürich, and Department of Environmental Microbiology, Eawag, Dübendorf, Switzerland

Received: 8 March 2010 Accepted: 26 May 2010

Published: 26 May 2010

\section{References}

1. Gogarten JP, Townsend JP: Horizontal gene transfer, genome innovation and evolution. Nat Rev Microbiol 2005, 3:679-682.

2. Gaillard M, Pernet N, Vogne C, Hagenbüchle O, Meer JR van der: Host and invader impact of transfer of the clc genomic island into Pseudomonas aeruginosa PAO1. Proc Natl Acad Sci USA 2008, 105:7058-7063.

3. Frost LS, Leplae R, Summers AO, Toussaint A: Mobile genetic elements: the agents of open source evolution. Nat Rev Microbio/ 2005, 3:722-732.

4. Toussaint A, Merlin C: Mobile elements as a combination of functional modules. Plasmid 2002, 47:26-35

5. Adamczyk M, Jagura-Burdzy G: Spread and survival of promiscuous IncP-1 plasmids. Acta Biochim Pol 2003, 50:425-453.

6. Thomas CM: Transcription regulatory circuits in bacterial plasmids. Biochem Soc Trans 2006, 34:1072-1074

7. Christie PJ, Atmakuri K, Krishnamoorthy V, Jakubowski S, Cascales E: Biogenesis, architecture, and function of bacterial type IV secretion systems. Annu Rev Microbiol 2005, 59:451-485.

8. Ptashne M: A Genetic Switch: Phage Lamba Revisited. Third edition. Cold Spring Harbor, New York: Cold Spring Harbor Laboratory Press; 2004. 
9. Osterhout RE, Figueroa IA, Keasling JD, Arkin AP: Global analysis of host response to induction of a latent bacteriophage. BMC Microbio/ 2007, 7:82.

10. Juhas M, Meer JR van der, Gaillard M, Harding RM, Hood DW, Crook DW: Genomic islands: tools of bacterial horizontal gene transfer and evolution. FEMS Microbiol Rev 2009, 33:376-393.

11. Hacker J, Carniel E: Ecological fitness, genomic islands and bacterial pathogenicity: A Darwinian view of the evolution of microbes. $E M B O$ Rep 2001, 2:376-381.

12. Dobrindt U, Hochhut B, Hentschel U, Hacker J: Genomic islands in pathogenic and environmental microorganisms. Nat Rev Microbiol 2004, 2:414-424

13. Mathee K, Narasimhan G, Valdes C, Qiu X, Matewish JM, Koehrsen M Rokas A, Yandava CN, Engels R, Zeng E, Olavarietta R, Doud M, Smith RS, Montgomery P, White JR, Godfrey PA, Kodira C, Birren B, Galagan JE, Lory S: Dynamics of Pseudomonas aeruginosa genome evolution. Proc Nat Acad SciUSA 2008, 105:3100-3105.

14. Beaber JW, Hochhut B, Waldor MK: Genomic and functional analyses of SXT, an integrating antibiotic resistance gene transfer element derived from Vibrio cholerae. J Bacterio/ 2002, 184:4259-4269.

15. Ramsay JP, Sullivan JT, Stuart GS, Lamont IL, Ronson CW: Excision and transfer of the Mesorhizobium loti R7A symbiosis island requires an integrase IntS, a novel recombination directionality factor RdfS, and a putative relaxase RIxS. Mol Microbiol 2006, 62:723-734.

16. Juhas M, Crook DW, Dimopoulou ID, Lunter G, Harding RM, Ferguson DJ, Hood DW: Novel type IV secretion system involved in propagation of genomic islands. J Bacterio/ 2007, 189:761-771.

17. Burrus V, Waldor MK: Control of SXT integration and excision. J Bacteriol 2003, 185:5045-5054

18. Beaber JW, Hochhut B, Waldor MK: SOS response promotes horizontal dissemination of antibiotic resistance genes. Nature 2004, 427:72-74.

19. Klockgether J, Wurdemann D, Wiehlmann L, Tummler B: Transcript profiling of the Pseudomonas aeruginosa genomic islands PAGI-2 and pKLC102. Microbiology 2008, 154:1599-1604

20. Gaillard M, Vallaeys T, Vorholter FJ, Minoia M, Werlen C, Sentchilo V, Puhler A, Meer JR van der: The clc element of Pseudomonas sp. strain B13, a genomic island with various catabolic properties. J Bacterio/ 2006 188:1999-2013.

21. Ravatn R, Studer S, Springael D, Zehnder AJB, Meer JR van der: Chromosomal integration, tandem amplification, and deamplification in Pseudomonas putida F1 of a 105-kilobase genetic element containing the chlorocatechol degradative genes from Pseudomonas sp. strain B13. J Bacteriol 1998, 180:4360-4369.

22. Ravatn $R$, Studer S, Zehnder AJB, Meer JR van der: Int-B13, an unusual site-specific recombinase of the bacteriophage $\mathrm{P} 4$ integrase family, is responsible for chromosomal insertion of the 105-kilobase clc element of Pseudomonas sp. strain B13. J Bacteriol 1998, 180:5505-5514.

23. Sentchilo V, Czechowska K, Pradervand N, Minoia M, Miyazaki R, Meer JR van der: Intracellular excision and reintegration dynamics of the ICEclc genomic island of Pseudomonas knackmussii sp. strain B13. Mol Microbiol 2009, 72:1293-1306.

24. Mohd-Zain Z, Turner SL, Cerdeño-Tárraga AM, Lilley AK, Inzana TJ, Duncan AJ, Harding RM, Hood DW, Peto TE, Crook DW: Transferable antibiotic resistance elements in Haemophilus influenzae share a common evolutionary origin with a diverse family of syntenic genomic islands. $J$ Bacterio/ 2004, 186:8114-8122.

25. Sentchilo VS, Zehnder AJB, Meer JR van der: Characterization of two alternative promoters and a transcription regulator for integrase expression in the clc catabolic genomic island of Pseudomonas sp. strain B13. Mol Microbiol 2003, 49:93-104.

26. Minoia M, Gaillard M, Reinhard F, Stojanov M, Sentchilo V, Meer JR van der: Stochasticity and bistability in horizontal transfer control of a genomic island in Pseudomonas. Proc Natl Acad Sci USA 2008, 105:20792-20797.

27. Sentchilo VS, Ravatn R, Werlen C, Zehnder AJB, Meer JR van der: Unusual integrase gene expression on the clc genomic island of Pseudomonas sp. strain B13. J Bacteriol 2003, 185:4530-4538.

28. Guell M, van Noort V, Yus E, Chen WH, Leigh-Bell J, Michalodimitrakis K, Yamada T, Arumugam M, Doerks T, Kuhner S, Rode M, Suyama M, Schmidt S, Gavin AC, Bork P, Serrano L: Transcriptome complexity in a genomereduced bacterium. Science 2009, 326:1268-1271.
29. Miyakoshi M, Nishida H, Shintani M, Yamane H, Nojiri H: High-resolution mapping of plasmid transcriptomes in different host bacteria. BMC Genomics 2009, 10:12.

30. Alonso S, Bartolome-Martín D, del Alamo M, Diaz E, Garcia JL, Pérera J: Genetic characterization of the styrene lower catabolic pathway of Pseudomonas sp. strain Y2. Gene 2003, 319:71-83.

31. Lambertsen L, Molin S, Kroer N, Thomas CM: Transcriptional regulation of pWW0 transfer genes in Pseudomonas putida KT2440. Plasmid 2004, 52:169-181.

32. Moreno R, Marzi S, Romby P, Rojo F: The Crc global regulator binds to an unpaired A-rich motif at the Pseudomonas putida alkS mRNA coding sequence and inhibits translation initiation. Nucleic Acids Res 2009 37:7678-7690.

33. Sonnleitner E, Abdou L, Haas D: Small RNA as global regulator of carbon catabolite repression in Pseudomonas aeruginosa. Proc Natl Acad SCi USA 2009, 106:21866-21871.

34. Gerhardt P, Murray RGE, Costilow RN, Nester EW, Wood WA, Krieg NR, Briggs Phillips $G$, (eds): Manual of methods for general bacteriology. Washington, D.C.: American Society for Microbiology; 1981.

35. Baumann B, Snozzi M, Zehnder AJB, Meer JR van der: Dynamics of denitrification activity of Paracoccus denitrificans in continuous culture during aerobic-anaerobic changes. J Bacteriol 1996, 178:4367-4374.

36. Rouillard JM, Zuker M, Gulari E: OligoArray 2.0: design of oligonucleotide probes for DNA microarrays using a thermodynamic approach. Nucleic Acids Res 2003, 31:3057-3062.

37. Shaner NC, Campbell RE, Steinbach PA, Giepmans BN, Palmer AE, Tsien RY: Improved monomeric red, orange and yellow fluorescent proteins derived from Discosoma sp. red fluorescent protein. Nat Biotechnol 2004, 22:1567-1572

38. Charbonnier $Y$, Gettler B, Francois $P$, Bento $M$, Renzoni A, Vaudaux $P$, Schlegel W, Schrenzel J: A generic approach for the design of wholegenome oligoarrays, validated for genomotyping, deletion mapping and gene expression analysis on Staphylococcus aureus. BMC Genomics 2005, 6:95.

39. Bolstad BM, Irizarry RA, Astrand M, Speed TP: A comparison of normalization methods for high density oligonucleotide arrays based on bias and variance. Bioinformatics 2003, 19:185-193.

40. Irizarry RA, Hobbs B, Collin F, Beazer-Barclay YD, Antonellis KJ, Scherf U, Speed TP: Exploration, normalization, and summaries of high density oligonucleotide array probe level data. Biostatistics 2003, 4:249-264.

doi: 10.1186/1471-2180-10-153

Cite this article as: Gaillard et al., Transcriptome analysis of the mobile genome ICEclc in Pseudomonas knackmussii B13 BMC Microbiology 2010 10:153

\section{Submit your next manuscript to BioMed Central and take full advantage of:}

- Convenient online submission

- Thorough peer review

- No space constraints or color figure charges

- Immediate publication on acceptance

- Inclusion in PubMed, CAS, Scopus and Google Scholar

- Research which is freely available for redistribution
C Biomed Central 